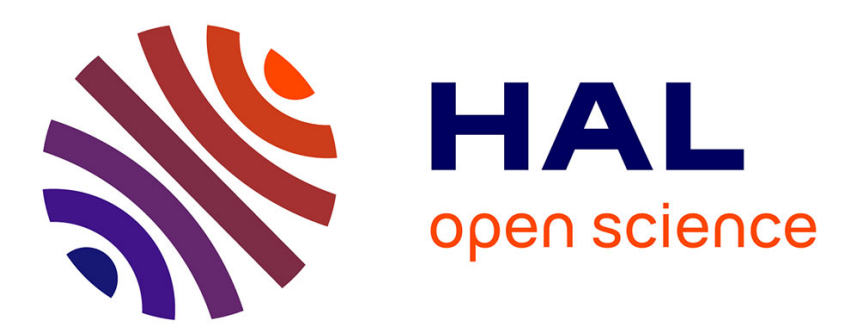

\title{
Optimal commodity grouping in a partial equilibrium framework
}

Pascal Belan, Stéphane Gauthier

\section{To cite this version:}

Pascal Belan, Stéphane Gauthier. Optimal commodity grouping in a partial equilibrium framework. Economics Letters, 2004, 83 (1), pp.49-54. 10.1016/j.econlet.2003.09.026 . halshs-00106895

\section{HAL Id: halshs-00106895 https://shs.hal.science/halshs-00106895}

Submitted on 12 Sep 2012

HAL is a multi-disciplinary open access archive for the deposit and dissemination of scientific research documents, whether they are published or not. The documents may come from teaching and research institutions in France or abroad, or from public or private research centers.
L'archive ouverte pluridisciplinaire HAL, est destinée au dépôt et à la diffusion de documents scientifiques de niveau recherche, publiés ou non, émanant des établissements d'enseignement et de recherche français ou étrangers, des laboratoires publics ou privés. 


\title{
Optimal Commodity Grouping in a Partial Equilibrium Framework
}

\author{
Pascal Belan \\ LEN-C3E, Université de Nantes, and EUREQua \\ Stéphane Gauthier \\ CREST-LMA, and GEMMA, Université de Caen
}

October 10, 2003

\begin{abstract}
A bstract
This note characterizes, in a partial equilibrium economy with a single agent, which commodities should be taxed whenever there is only one available tax rate. We show that commodities with low price elasticities should be imposed; luxuries are eventually exempted.
\end{abstract}

JEL classi..cation number: H21.

Key words: optimal indirect taxation, commodity grouping.

- Corresponding author: Stéphane Gauthier, CREST-LMA, 15 bd Gabriel Péri, 92245 Malako cedex, France; Phone number: + 33141173738; Fax number: + 33141177666; E-mail address: gauthier@ensae.fr.

${ }^{y}$ We wish to thank Guy Laroque for numerous advices and comments. 


\section{Introduction}

The literat ure on indirect taxation focuses on Ramsey's (1927) con.guration in which the number of possible diderent tax rates equals the number of commodities. In this event the structure of optimal taxation is characterized by the inverse elasticity rule discussed in Baumol and Bradford (1970), as it involves t ax rates being inversely proportional to the price elasticity of demand for each commodity. Most countries, however, implement tax policies where the number of available tax rates is less than the number of goods. In a second best tradition this could result from administrative costs of tax collection (see, e.g. Yitzhaki, 1979).

Diamond (1973) takes into account these restrictions and derives optimal partial tax rates under the assumption that the groups of commodities taxed at the same rate are arbitrarily given. It remains, therefore, to determine the optimal grouping structure, i.e. the optimal allocation of commodities to groups. Gordon (1989) provides early insights on this issue by using a tax reform methodology. He shows that it is typically welfare improving to tax at the same rate consumption goods with possibly very dixerent price elasticity, which suggest $s$ that the inverse elast icity rule could then fail. ${ }^{1}$

This not es characterizes the optimal grouping structure in a partial equilibrium framework where there is a single consumer, an arbitrary number of commodities and only one available tax rate. It highlights that both price elasticity and budget share of commodities matter for the determination of the optimal $t$ ax rule; for e $\phi$ ciency reasons the social planner prefers taxing commodities with large budget share and low price elasticity. Still, when the required government revenue is low enough, the optimal group is shown to be connected, in the sense that if some commodity is exempted from taxation, then any commodity with a higher price elasticity is also exempted.

This note is organized in the following way. First, it describes the optimal grouping problem. Then, it characterizes the optimal group of taxed commodi$t$ ies in the case of a represent ative agent, and it establishes that this group is connected according to price elasticity. A consequence of this property is to concentrate taxation on necessities and to release luxuries from any tax. Thus, in order to collect ..scal revenue, necessities may be taxed more heavily than recommended by the Ramsey rule, which strengt hens the traditional conłict between e $\phi$ ciency and equity.

\footnotetext{
1 See Proposition 2 in Gordon (1989), where tax reforms start from a uniform tax rate. Note that if, however, the set of feasible reforms is restricted in a suitable way, then it is socially optimal to group commodities with similar price elasticity.
} 


\section{The optimal grouping problem}

We consider a standard part ial equilibrium analysis with $\mathrm{n}$ commodities and labor as numeraire. The preferences of the representative consumer are described by

$$
\mathrm{U}\left(\mathrm{X}_{1} ;::: ; \mathrm{X}_{n} ; \mathrm{L}\right)=\mathrm{X}_{\mathrm{i}=1}^{\mathrm{n}} \mathrm{U}_{\mathrm{i}}\left(\mathrm{X}_{\mathrm{i}}\right) \mathrm{i} \mathrm{L},
$$

where $X_{i}(i=1 ;::: ; n)$ is the amount of consumption good $i$ purchased, and $L$ is the amount of labor supplied. The function $U_{i}(\phi)$ is increasing and concave. Producer prices are constant; they are set at unity without loss of generality. Then, consumer prices are $\left(1+t_{i}\right)$, where $t_{i}$ is the tax rate on commodity $i$. As usual the consumer is assumed to maximize his utility function (1) subject to the budget constraint

$$
X_{i=1}^{n}\left(1+t_{i}\right) X_{i} \cdot L \text {. }
$$

Let $X_{i}\left(t_{i}\right)$ and $L\left(t_{1} ;:: ; t_{n}\right)$ be the solution of the consumer program.

The classical Ramsey problem amounts to choose the tax rates maximizing welfare $U\left(X_{1}\left(t_{1}\right) ;:: ; X_{n}\left(t_{n}\right) ; L\left(t_{1} ;:: ; ; t_{n}\right)\right)$ under the constraint that the government collects a certain . scal revenue $R$,

$$
X_{i=1}^{n} t_{i} X_{i}\left(t_{i}\right), R \text {. }
$$

It is well known (see Atkinson and Stiglitz, 1980, Lecture 12) that the solution to this problem involves the tax rate being in inverse proportion to the price elasticity of demand ${ }_{i}\left(t_{i}\right)=i\left(1+t_{i}\right) X_{i}^{0}\left(t_{i}\right)=X_{i}\left(t_{i}\right)$. Hence Ramsey tax rates are not uniform whenever commodities diaer according to price elasticity.

In this paper, we depart from this framework in restricting the number of possible diderent $t$ ax rates. We consider that some commodities are taxed at a unique rate, while the others (and labor) are exempted from taxation. ${ }^{2}$ Let $\mathrm{G}$ denote the group of taxed commodities, i.e. $t_{i}=t>0$ if i $2 \mathrm{G}$, and $t_{i}=0$ otherwise. Let also

$$
" G(t),{ }_{i 2 G^{1 / 4 G(t)}}^{\frac{1 / 4 i}{1 / G}(t)}
$$

\footnotetext{
2 Most of value-added tax systems use two diaerent tax rates, a normal and a reduced one. In general, however, the ..r.st rate al lows to collect most of the tax, which may justify our assumption of a single tax rate. The main VAT rate is charged at $17.5 \%$ in the United Kingdom, and at $19,6 \%$ in France (it yields about $90 \%$ of the French VAT tax). The United States relies on a system of retail sales taxes de..ned at the state level. Although the US have a low reliance on such taxes, some have proposed to introduce a single tax rate of $15 \%$ on every ...nal good or service that is consumed (National Ret ail Sales Tax Act of 1997).
} 
be the price elasticity of group G, where

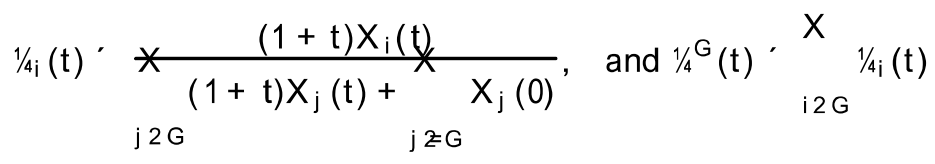

stand for the budget share of commodity $i$ and group $G$, respectively. For a given group G, the government constraint (3) satis..ed at equality implicitly de. nes the tax rate $t^{G}(R)$ as a function of ..scal revenue. By de..nition, the optimal group $G^{\mathbb{a}}$ maximizes

$$
V(R ; G){ }^{\prime} U\left(X_{1}\left(t_{1}^{G}(R)\right) ;:: ; X_{n}\left(t_{n}^{G}(R)\right) ; L\left(t_{1}^{G}(R) ;:: ; t_{n}^{G}(R)\right),\right.
$$

with the restriction that $t_{i}^{G}(R)=t^{G}(R)>0$ if i $2 G$, and $t_{i}^{G}(R)=0$ if $i z G$.

\section{Characterization of the optimal group}

Our .r.st result allows to compare social welfare for two dixerent groups of taxed commodities. It is derived under the assumption that .scal revenue is low enough, i.e. in the so-called small government case.

Lemma 1 Let $R$ be arbitrarily close to 0 . Consider two groups $G_{1}$ and $G_{2}$ of taxed commodities. Then $V\left(R ; G_{1}\right)>V\left(R ; G_{2}\right)$ if and only if

$$
\frac{"\left(G_{1}\right)}{1 / 4\left(G_{1}\right)}<\frac{"\left(G_{2}\right)}{1 / 4\left(G_{2}\right)}
$$

where " $\left(G_{i}\right)$ and $1 / 4\left(G_{i}\right)$ stand for " $G_{i}(0)$ and $1 / 4 G_{i}(0)$, respectively.

Proof. Observe that if $R$ is close enough to 0 , then the shadow price of .scal revenue is independent of the group of commodities taxed at a positive rate. Indeed, the ..rst derivative $\mathrm{V}^{0}(R ; G)$ of indirect utility function with respect to .scal revenue equals $; 1$ if $R=0$, so that $t^{G}(0)=0$ what ever $G$ is. Thus, $V\left(R ; G_{1}\right)>V\left(R ; G_{2}\right)$ is equivalent to $V^{00}\left(R ; G_{1}\right)>V^{00}\left(R ; G_{2}\right)$, where $V^{00}(R ; G)$ stands for the second derivative of $V$ with respect to $R$. It is then straightforward to show that

$$
V^{00}(0 ; G)={ }_{i 2 G}^{\tilde{A}} X_{i}(0) !_{i 2}{ }^{\tilde{A}} X_{i}(0) \text { ! }
$$

For $t^{G}(R)=0$, the price elasticity of commodity $i$ equals $i X_{i}^{0}(0)=X_{i}(0)$. Thus, after using both (4) and $(5), V^{00}\left(R ; G_{1}\right)>V^{00}\left(R ; G_{2}\right)$ rewrites as in Lemma 1 , which concludes the proof.

When a constraint on the number of possible dixerent tax rates is taken into account, the fact that a commodity has to be taxed at the social optimum depends not only on its price elasticity, but also on its budget share. Of course, 
it is always welfare improving to tax a commodity $\mathrm{j}$ with a low price elasticity, as this makes higher the budget share of the group of taxed commodities and lower the price elasticity of this group. More generally, if ${ }_{j}<"(G)$, then $V(R ; G[f j g)>V(R ; G)$. For any other commodity, the exect on social welfare is a priori ambiguous since int roducing a commodity $j$ with ${ }_{j}>"(G)$ into group $G$ increases simultaneously the budget share and the price elasticity of the group of taxed commodities. Our next result is concerned with these commodities.

Corollary 2 Let $R$ be arbitrarily close to 0 . Consider a group $\mathrm{G}$ of commodities taxed at a positive rate, and a commodity $j z G$ such that " $>$ > "(G). Then, introducing commodity $j$ into $G$ is welfare improving, i.e. $V(R ; G[f j g)>$ $V(R ; G)$ if and only if ${ }_{j}<"(G)+"(G[f j g)$.

Proof. It directly follows from Lemma 1 that $V(R ; G[\mathrm{fjg})>V(R ; G)$ holds true if and only if $1 / 4(G) "(G[f j g)<1 / 4(G[f j g) "(G)$. After straightforward manipulations, this condition rewrites

$$
(1 / 4(G)+1 / 4 j)(" j i \quad "(G))<1 / 4 j ~{ }_{j}+1 / 4(G) "(G) .
$$

Using (4) and (5) leads to the result.

Hence, a commodity with high price elasticity is taxed only if its budget share is large enough, and one could expect the optimal group $G^{\text {a }}$ to be not connect ed if the exect of budget share is strong enough to overcome the exect of price elasticity. Some commodities would be then exempted from taxation, while commodities with higher price elasticity would be taxed. This cannot arise, however, as Proposition 3 below shows.

Proposition 3 Let $R$ be arbitrarily close to 0 . Consider a group $G$ of commodities taxed at a positive rate, and a commodity $k z G$ with "k $>$ "(G). Suppose that introducing commodity $k$ into the group $G$ is welfare improving, i.e. $V(R ; G[f \mathrm{~kg})>V(R ; G)$. Then introducing any commodity $j z G$ with ${ }_{j}<{ }_{k}$ into $G$ is also welfare improving, i.e. $V(R ; G[f j ; k g)>V(R ; G[f k g)$.

Proof. Suppose that $V(R ; G[f \mathrm{~kg})>V(R ; G)$. It follows from Corollary 2 that "k $<"(G)+"\left(G[f k g)\right.$. Since " $(G)<{ }_{k}$, we have " $(G)<"(G[f k g)$, and so

$$
{ }_{k}<"(G)+"(G[f k g)<2 "(G[f k g) \text {. }
$$

Observe now that $V(R ; G[f j ; k g)>V(R ; G[f k g)$ rewrites, using Lemma 1 , $1 / 4(G[f k g) "(G[f j ; k g)<1 / 4(G[f j ; k g) "(G[f k g)$, which is equivalent to

$$
\mu+\frac{1 / 4 j}{1 / 4(G)+1 / 4 k}=\left(G[f k g)>{ }_{j}\right. \text {. }
$$

We now proceed by cont radiction to show that $V(R ; G[f k g)>V(R ; G)$ implies $V(R ; G[f j ; k g)>V(R ; G[f k g)$. Assuming $V(R ; G[f j ; k g) \cdot V(R ; G[f k g)$, 
it follows from (7) that

$$
"\left(G[f k g) \cdot \frac{1}{2} "_{j}<\frac{1}{2}{ }_{k},\right.
$$

which is inconsistent with (6), and thus concludes the proof.

It follows that the optimal grouping structure does not violat e Ramsey primary insights: it is connected in the sense that if some commodity is exempted from taxation, then any commodity with a higher price elasticity is also exempted. Moreover, by Corollary 2, the optimal group involves taxing all the commodities with a low price elasticity, while the others are not subject to taxation. This observation provides a simple method to determine the opt imal grouping structure. Let us rank consumption goods in the order of increasing elasticity of demand, i.e. " ${ }_{i}<{ }_{j}$ whenever $i<j(i ; j=1 ;:: ; n)$. Then, Proposition 3 implies that there is a unique commodity $s^{\infty}\left(1 \cdot s^{\alpha} \cdot n\right)$ such that $t_{i}^{G^{a}}(R)=t^{G^{\alpha}}(R)>0$ for $i \cdot s^{\alpha}$ and $t_{i}^{G^{a}}(R)=0$ for $i>s^{a}$. By Corollary 2 , the threshold $s^{\mathfrak{a}}$ is the lowest index such that ${ }_{i}={ }_{1}{ }_{1}>2+1 / 4 \mathrm{i}=1 / 41$ for any $i>s^{\mathfrak{a}}$. That is, if price elast icities are high with respect to the elasticity of commodity 1 , then the scope of taxation, measured by the optimal number of commodities taxed at a positive rate, tends to shrink. More generally, there is a narrower scope for taxation whenever the diaerence between high and low price elasticities is widening. On the ot her hand, the opt imal number of taxed commodities tends to increase if commodit ies with low price elast icity have also low budget shares. Indeed, if consumer expenditures are biased in favor of commodit ies with high price elasticity, the government will be forced to enlarge the basis for taxation to collect a given amount of ..scal liabilities.

It is often argued that Ramsey taxation gives rise to a trade-o between e $\phi$ ciency and equity because the inverse elasticity rule implies that commodities with low price elasticity are taxed more heavily, and these commodities are consumed in a large proportion by poor individuals. The previous result shows that this confict is likely to be strengthened in our framework since the burden of taxation may essentially bear on low income individuals. It is further reinforced if one considers the level of the optimal tax rate $t^{G^{a}}(R)$ maximizing e $\phi$ ciency of the tax system, as our next result highlights.

Proposition 4 Let $R$ be arbitrarily close to 0 . Let $i_{i}(R)$ be the Ramsey tax rate; by the inverse elasticity rule, $i_{1}(R),:::, i_{n}(R)$. If the number of taxed commodities $s^{\alpha}$ of the optimal group $G^{\alpha}$ is less than a threshold $\$$, then $t^{G^{a}}(R)>i_{1}(R)$. On the contrary, if $s^{a}>s$, then $t^{G^{a}}(R)<i_{1}(R)$.

Proof. We .r.st prove that $t^{G_{1}}(R)>t^{G_{2}}(R)$ if $G_{1} 1 / 2 G_{2}$ whatever $G_{1}$ and $G_{2}$ are. Since the government budget constraint is binding what ever $G$ is, $G_{1} 1 / 2 G_{2}$ implies

$$
t^{G_{1}}(R){ }_{i 2 G_{1}}^{X} X_{i}\left(t^{G_{1}}(R)\right)>t^{G_{2}}(R){ }_{i 2 G_{1}}^{X} X_{i}\left(t^{G_{2}}(R)\right):
$$


Observe now that ..scal revenue is an increasing function of tax rates whenever $R$ is close enough to 0 . Thus there exists $s, 1 \cdot s \cdot n$, such that $t^{a}(R)<t_{1}(R)$ if and only if $s^{a}>s$. In fact, it could be easily shown that $2 \cdot s \cdot n$.

Therefore, in a society where the optimal number of taxed commodities is large enough, the tax rate on necessities becomes lower than Ramsey tax rates. Given that the optimal group is connected, the social planner will compensate the ..scal loss on necessit ies by imposing a tax rate on goods with medium price elasticity higher than Ramsey tax rates, whereas luxuries should avoid taxation in general. Nevertheless, the optimal tax structure is quite dixerent in a poor society: necessities are then the only taxed commodities and they should be $t$ axed at a higher rate than recommended by Ramsey's rule.

\section{References}

Atkinson, A.B. and J.E. Stiglitz, 1980, Lectures on public economics (McGrawHill international editions).

Baumol, W.J. and D.F. Bradford, 1970, Optimal departures from marginal cost pricing, American Economic Review 60, 265-283.

Diamond, P.A., 1973, Taxation and public production in a growth setting, in: J.A. Mirrlees and N.H. Stern, eds., Models of economic growth (IEA McMillan, London) 215-235.

Gordon, J.P.F., 1989, Tax reform via commodity grouping, Journal of Public Economics 39, 67-81.

Ramsey, F.P., 1927, A cont ribution to the theory of taxation, Economic Journal $37,47-61$.

Yitzhaki, S., 1979, A not e on opt imal taxation and administrative cost s, American Economic Review 69, 475-480. 